\title{
Complete colonic closure with an over-the-scope clip placed for a colorectal anastomotic fistula: a big mistake
}

Colorectal postsurgical leaks and fistulas are severe complications that increase morbidity and mortality. The recent development of the over-the-scope clip (OTSC) has dramatically decreased the number of surgical reinterventions required [1].

A 73-year-old man with a history of anterior rectal resection for a T3N1 adenocarcinoma and subsequent neoadjuvant chemotherapy was referred to our unit because of a suspicion of a colorectal fistula, which had developed 30 days after the surgical intervention. A lower gastrointestinal endoscopy showed the colorectal anastomosis with a fistula $(9 \mathrm{~mm}$ in diameter) at $5 \mathrm{~cm}$ from the anal verge. We decided to close the defect with an 11/6t OTSC (Ovesco, Tübingen, Germany). Using a gastroscope, the suction technique, and with the aid of the anchor device, we placed an OTSC over the fistula but, after the clip was released, we observed a complete closure of the colonic lumen, also evidence by an absence of air coming from the bowel. Because of the memory loss of the nitinol in the clip at temperatures under $4^{\circ} \mathrm{C}$, we decided to irrigate the colonic lumen with cold water $\left(<4^{\circ} \mathrm{C}\right)$ for 10 minutes, until the color of

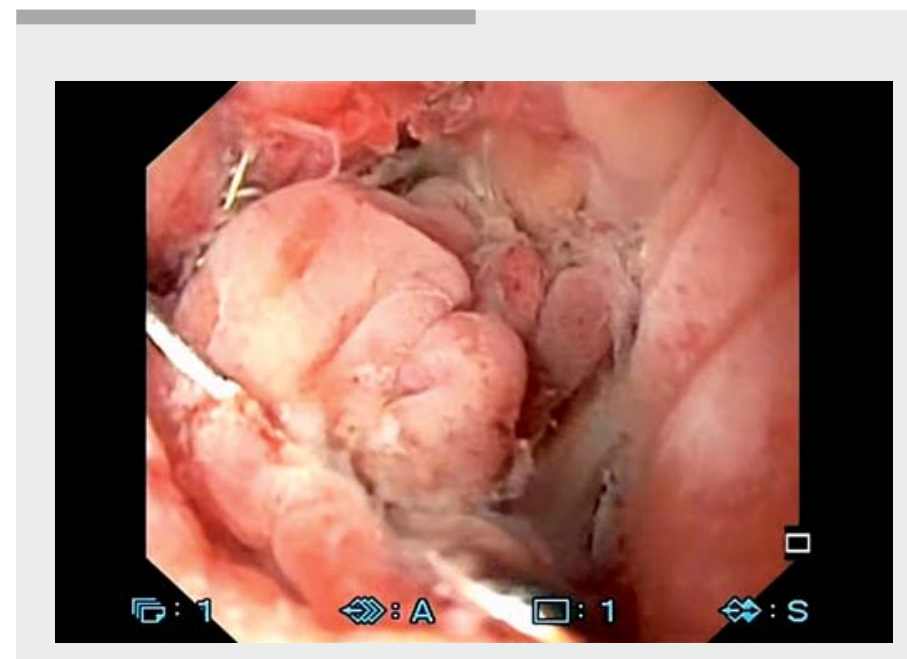

Video 1 Removal and replacement of a previously placed over-the-scope clip that caused complete closure of the colonic lumen.

the mucosa changed to white. Following this, we removed the OTSC using a rattooth forceps, without any complications. In the same session, following clip removal, we placed another $11 / 6$ t OTSC with the aid of the anchor device, successfully sealing the fistula ( $\vee$ Video 1 ). In conclusion, endoscopic OTSC closure of colorectal postsurgical leaks and fistu- las is a safe technique, with a high success rate in both acute and chronic cases. However complete bowel closure is a rare adverse event that can happen accidentally, especially in non-expert hands. The nitinol memory loss in water at $<4^{\circ} \mathrm{C}$ allowed OTSC deformation, which helped us in its removal.

Endoscopy_UCTN_Code_CPL_1AJ_2AG

Competing interests

The authors declare that they have no conflict of interest. 
The authors

Benedetto Mangiavillano ${ }^{1,2}$, Francesco Auriemma ${ }^{1}$, Mario Bianchetti ${ }^{1}$, Alessandro Repici ${ }^{2,3}$

1 Gastrointestinal Endoscopy Unit, Humanitas Mater Domini, Castellanza, Varese, Italy

2 Humanitas University, Milan, Italy

3 Digestive Endoscopy Unit, Istituto Clinico Humanitas Research Hospital, Milan, Italy
Corresponding author

Benedetto Mangiavillano, MD

Gastrointestinal Endoscopy Unit, Humanitas

- Mater Domini, Via Gerenzano n.2,

21053 Castellanza (VA), Italy

bennymangiavillano@gmail.com

Reference

[1] Singh RR, Nussbaum JS, Kumta NA. Endoscopic management of perforations, leaks and fistulas. Transl Gastroenterol Hepatol 2018; 3: 85
Bibliography

DOI https://doi.org/10.1055/a-1073-7445

Published online: 20.12.2019

Endoscopy 2020; 52: 521

(c) Georg Thieme Verlag KG

Stuttgart $\cdot$ New York

ISSN 0013-726X 